\title{
Relations Between Psychosocial Job Characteristics and Work Ability in Employees with Chronic Headaches
}

\author{
Margot P. van der Doef ${ }^{1} \cdot$ Roosmarijn M. C. Schelvis ${ }^{2}$
}

Published online: 10 April 2018

(c) The Author(s) 2018

\begin{abstract}
Purpose The aim of the study was to determine (a) to which extent job demands and job resources predict work ability in employees with chronic headaches, and (b) whether work ability in these employees is more hampered by high demands and more enhanced by resources than in employees without chronic disease. Methods All employees with chronic headaches $(\mathrm{n}=593)$ and without chronic disease $(\mathrm{n}=13,742)$ were selected from The Netherlands Working Conditions Survey conducted in 2013. This survey assessed amongst others job characteristics and various indicators of work ability, i.e. sick leave, employability, work engagement, and emotional exhaustion. Hierarchical regression analyses were conducted for employees with chronic headaches and compared to employees without chronic disease, controlling for age, gender and educational level. Results In employees with chronic headaches higher quantitative and emotional demands contributed to higher emotional exhaustion, and higher emotional demands to higher sick leave. Higher cognitive demands were however associated with higher work engagement. Higher autonomy was related to higher employability and lower emotional exhaustion. Higher supervisor and colleague support was associated with higher employability, higher engagement and lower emotional exhaustion. Higher supervisor support was associated with lower sick leave. Supervisor support emerged as a stronger predictor for emotional exhaustion in the employees with chronic headaches than in the employees without chronic disease. Conclusions Job demands and job resources are important for work ability in employees with chronic headaches. Furthermore, results suggest that these employees benefit more strongly from supervisor support than employees without chronic disease.
\end{abstract}

Keywords Headache $\cdot$ Sick leave $\cdot$ Burnout $\cdot$ Workload $\cdot$ Social support

\section{Introduction}

Chronic headache(s), characterized by recurrent headaches, and including migraine, tension headache, and cluster headache, are among the most common disorders of the nervous system [1]. Globally, the prevalence of chronic headache(s) has been estimated at $46 \%$ for headache in general, $11 \%$ for migraine, $42 \%$ for tension-type headache, and $3 \%$ for chronic daily headache [2]. Where studies have often focused on migraine, other types of headaches have received less

Margot P. van der Doef

doef@fsw.leidenuniv.nl

1 Institute of Psychology, Health, Medical, and Neuropsychology Unit, Leiden University, Leiden, The Netherlands

2 Netherlands Organization for Applied Scientific Research TNO, Work, Health \& Technology, Leiden, The Netherlands attention [3]. Chronic headache(s) are most prevalent in the age group 18-50, and as such affect the working population [1].

Concerning the impact of headache on work, headaches have been associated with various indicators of reduced work ability. In a population-based study in Sweden, frequent headache was associated with poor mental and physical work ability, but unrelated to sickness absence [4]. In other studies headaches have been shown to relate to both higher absenteeism and reduced productivity at work $[2,5]$. Migraine, as a specific headache disorder, was responsible for an average loss of $4.6 \mathrm{~h}$ of work productivity per week [6]. A review study on the impact of migraine on work productivity in the United States estimated that an employee with migraine loses on average four workdays per year due to headaches [7]. Illustrative of the high impact of chronic headache(s) were the findings of The Global Burden of Disease Study [8] identifying chronic headache(s) third among 
the worldwide causes of disability, measured in years of life lost to disability.

Given the reduced work ability in employees with chronic headache(s), it is important to determine in which way work ability in these employees can be optimized. The current study examined the relationship between psychosocial job characteristics and work ability indicators in a sample of employees with chronic headaches, in order to identify those job characteristics that could be targeted to improve and maintain work ability in these employees.

The psychosocial characteristics of a job have been widely studied as determinants of employees' job related well-being and functioning [9-11]. Two of the main models in this regard, the Job Demands-Control-Support (JDCS) model and the Job Demands-Resources (JDR) model, discern two types of job characteristics [12-15]. The first type includes the job demands, which are considered to exert their influence on well-being and functioning through an energy depleting pathway. Job demands include the quantitative, emotional, and cognitive demands the job poses on the employee. The second type of job characteristics includes the job resources, which are expected to have a positive effect on functioning through a motivational pathway [16]. Job resources are positive job aspects that are functional in achieving work goals, reduce job demands and the associated costs, and stimulate personal growth, learning, and development. The resources most commonly studied are autonomy, and social support from colleagues and supervisor. Research has related job demands and job resources to various indicators of work ability (see e.g., [17]). High job resources were associated with high employability [18], high engagement, and low burnout [19]. In contrast, high demands impeded work ability [20], and were related to burnout and low engagement [19]. In a longitudinal study, Airila et al. [21] found high job resources to be predictive for work engagement and future work ability. Furthermore, changes in job demands and resources have shown to have an impact on burnout, work engagement, and sickness absenteeism [22].

The current study examined whether job demands are negatively, and job resources are positively associated with indicators of work ability in employees with chronic headaches as is proposed in the JDR model. The following outcomes were included as indicators of work ability: emotional exhaustion, work engagement, employability, and sick leave.

Hypothesis 1 In employees with chronic headaches, higher (quantitative, emotional, and cognitive) job demands are associated with reduced work ability.

Hypothesis 2 In employees with chronic headaches, higher job resources (i.e. autonomy, and social support from supervisor and colleagues) are associated with higher work ability.
Furthermore, it was examined whether these associations are stronger for employees with chronic headaches than for employees without a chronic condition. Limited research has thus far addressed this issue. A cross-sectional study on university employees analyzing relationships between job characteristics and fatigue, exhaustion, and health complaints found overall comparable relationships for employees with and without chronic disease [23]. Only unpleasant treatment (i.e. experiencing discrimination) proved to be a stronger correlate of outcomes for the employees with chronic disease, and there were indications that social support from superiors was a more important resource for employees with chronic disease. The latter is in line with the findings from a study on employees with diverse chronic illnesses [24].

Focusing on employees with chronic headaches, we expected that high job demands have a stronger impact on their work ability, as their (working) capacity is already taxed by their health status. Furthermore, one would expect high job demands to contribute to the severity and frequency of headache episodes. Longitudinal research has found a strong association between experienced stress and the frequency and intensity of tension headache [25], and there is also, though more limited, evidence linking migraine to stress [26]. More specific for work-related stress, Christensen and Knardahl found higher quantitative demands, higher role conflict, and low job control to be prospectively related to more severe headache at followup [27].

On the other hand, we expected employees with chronic headache to benefit more from the job resources autonomy and social support than employees without chronic conditions do. High levels of autonomy would enable employees to adapt their work schedule and workload to their condition on a daily basis. Job control furthermore has been shown to act as a buffer in the association between decreased work ability and productivity loss [28]. We expected social support from supervisor and colleagues to be a more valuable resource for employees with chronic headache, providing them with understanding and support in periods of reduced capacity due to recurrent headaches. The importance of a good social climate for work ability of chronically ill employees has been well documented [23, 24, 29].

Hypothesis 3 Quantitative, emotional, and cognitive job demands will be more strongly negatively associated with work ability in employees with chronic headaches than in employees without a chronic condition.

Hypothesis 4 Job resources (autonomy and social support) will be more strongly positively associated with work ability in employees with chronic headaches than in employees without a chronic condition. 
Summarizing, the current study examined in a representative sample of employees with chronic headache which psychosocial job characteristics predicted work ability, and determined whether the work ability in this group was more hampered by job demands and more enhanced by job resources in comparison to employees without chronic condition. The results of this study indicate whether it would be a fruitful avenue to focus on enhancing (specific) job characteristics in order to improve work ability in employees with chronic headaches.

\section{Methods}

\section{Sample}

Data were obtained from the Netherlands Working Conditions Survey (NWCS), a yearly survey that targets a representative sample of the Dutch working population aged between 15 and 65 years of age [30]. In 2013, 80,000 employees were randomly sampled from the working population, of which a total of 23,303 employees completed the questionnaire (response rate: $32.6 \%$ ). From this sample, employees with chronic headaches $(\mathrm{n}=593)$ and employees without any chronic disease $(n=13,139)$ were selected for analysis in the current study. All employees with any other chronic disease(s) than chronic headaches $(n=9571)$ were not included in the sample.

\section{Procedure}

The employees in the sample received a paper questionnaire with an invitation, an information brochure and an answering envelope at their home address. The questionnaire could be filled out on paper or online (NIPO Software suite) using a personal code. After 5 and 8 weeks reminder letters were sent. As an incentive for participation, participants could enter a lottery or choose to make a donation to a good cause.

\section{Measures}

\section{Demographics}

Data on demographics included gender (male/female), age (five categories: 15-24, 25-34, 35-44, 45-54, 55-65), educational level (low-primary school/lower vocational education, intermediate-intermediate secondary/vocational education, and high — higher vocational/university education), marital status (unmarried, married or in a partnership, widowed, or divorced), and household composition (married or living together without children living at home, married or living together with children at home, single parent household, living alone, or other household composition).

\section{Chronic Headaches}

Based on the question "Do you have one of the following chronic illnesses or handicaps?" participants indicating "migraine/severe headache" and no other illnesses or handicaps were selected as the study sample. A 'no chronic disease' comparison group was composed of those employees who indicated to have no chronic illness or handicap.

\section{Job Demands}

Quantitative demands was assessed using four items derived from the Job Content Questionnaire [30-32]. An example item is "do you have to work extra hard?" Emotional demands was determined using three items from the Copenhagen Psychosocial Questionnaire [33]. An example item is "is your work emotionally demanding?" Cognitive demands were based on three items derived from the Job Content Questionnaire. An example item is "does your work require concentration?" For all items, answering options ranged from $1=$ never to $4=$ always. The scores were computed as the mean score across the scales' items. The internal reliability of these scales was good in the NWCS 2013 sample $(\alpha=.83-.86)$ [30].

\section{Job Resources}

Autonomy refers to the extent employees are able to regulate their own work in terms of method, scheduling, and order. The five items were based on the Job Content Questionnaire. An example item is "can you arrange your own working times?". Answering options were $1=$ no, $2=$ yes, sometimes, and $3=$ yes, often. Social support supervisor and social support colleagues was assessed through four items on supervisor support and four items on co-worker support, also based on the Job Content Questionnaire. Example items are "my supervisor helps to get the work done", and "my colleagues are friendly" ( $1=$ completely disagree to $4=$ completely agree). The Cronbach's alpha of these three job resources scales was good in the NWCS 2013 sample $(\alpha=.78-.86)$ [30].

\section{Indicators of Work Ability}

Emotional exhaustion, as a core dimension of burnout, was assessed with five items based on the Dutch version of the Maslach Burnout Inventory [30, 34]. An example item is "my work makes me feel completely drained" $(0=$ never to $6=$ every day). Work engagement, as a positive outcome reflecting vigor, dedication, and absorption in work, was determined using three items derived from the Utrecht Work Engagement Scale [30, 35]. An example item is "At my job, I feel strong and vigorous" $(0=$ never to $6=$ every 
day). Employability refers to the ability to meet the mental and physical demands of the job, and the perceived future prospects. The scale consists of five items, developed for the NWCS. An example item is: "I can easily meet the physical demands of my job" $(1=$ completely disagree to $4=$ completely agree). The Cronbach's alpha of these three scales were acceptable to good in the NWCS sample $(\alpha=.69-.87)$ [30].

Sick leave was calculated based on the number of days an employee was absent over the past 12 months, corrected for part-time work, resulting in a sick leave percentage ranging from $0 \%=$ never absent to $100 \%=$ always absent. Besides this percentage, the frequency of sick leave in the past 12 months was assessed.

\section{Data Analyses}

As the variables sick leave percentage and sick leave frequency were severely skewed, the inverse for these variables was calculated, resulting in acceptable values for skewness and kurtosis. The transformed variables were reflected to facilitate interpretation.

To detect potentially confounding variables it was examined whether the employees with chronic headaches and the employees without chronic disease differed on socio-demographic characteristics, and whether socio-demographic characteristics were significantly related to both job characteristics and work ability indicators. Further analyses were controlled for these potential confounders.

Hierarchical multiple regression analyses were conducted to test the hypotheses. First, for the sample of employees with chronic headaches the indicators of work ability were regressed on the relevant socio-demographic characteristics (block 1) and the job characteristics (block 2). Next, this analysis was repeated on the combined sample of employees with chronic headache and employees without chronic disease: socio-demographic characteristics (block 1), group $(0=$ no chronic disease; $1=$ chronic headache) (block 2$)$, followed by the centered scores of the job characteristics (block 3 ), and the interaction terms between group and centered job characteristics (block 4). For the latter block a stepwise method (backwards) was used to reach a parsimonious model. A significance level of $p<.05$ was applied. All analyses were performed in IBM SPSS Statistics version 23 [36].

\section{Results}

Comparison of the chronic headache group and the no chronic disease group on socio-demographic characteristics indicated that the groups were comparable with regard to educational level, marital status and household composition (see Table 1). However, the chronic headache group included a larger percentage female employees (79 vs. $46 \%$, $\chi^{2}=128.92, p<.001$ ), and had a significantly different age composition with a higher percentage of the employees in the 35-44 age category than the group without chronic disease ( 29 vs. $24 \%, \chi^{2}=16.47, p<.01$ ). Furthermore, correlations indicated that age group, gender, and educational level were significantly related to both job characteristics and work ability indicators. Hence, all further analyses were controlled for age group, gender, and educational level.

Table 2 reports the Cronbach's alphas of the scales and the bivariate correlations of the variables under study. The Cronbach's alphas were acceptable to good $(\alpha=.70-.89)$ for all scales. Overall, the bivariate correlations between the psychosocial job characteristics and the work ability indicators for the chronic headache sample were in line with
Table 1 Socio-demographic characteristics of the employees with chronic headaches $(\mathrm{n}=593)$ and the employees without chronic disease $(\mathrm{n}=13,149)$

\begin{tabular}{|c|c|c|c|c|c|}
\hline & \multicolumn{2}{|c|}{ Chronic headache $(\mathrm{n}=593)$} & \multicolumn{2}{|c|}{ No chronic disease $(n=13,149)$} & \multirow[t]{2}{*}{$\chi^{2}$-test } \\
\hline & $\mathrm{N}$ & Percentage (\%) & $\mathrm{N}$ & Percentage (\%) & \\
\hline Gender & & & & & $128.92 * * *$ \\
\hline Male & 181 & 30.6 & 7153 & 54.4 & \\
\hline Female & 412 & 69.4 & 5996 & 45.6 & \\
\hline Age & & & & & $16.47 * *$ \\
\hline $15-24$ & 83 & 14.1 & 2321 & 17.7 & \\
\hline $25-34$ & 152 & 24.3 & 3224 & 24.5 & \\
\hline $35-44$ & 173 & 29.2 & 3197 & 24.3 & \\
\hline $45-54$ & 137 & 23.1 & 2869 & 21.8 & \\
\hline $55-64$ & 48 & 8.1 & 1538 & 11.7 & \\
\hline Educational level & & & & & 5.90 \\
\hline Low & 114 & 19.2 & 3022 & 23.0 & \\
\hline Intermediate & 273 & 46.0 & 5501 & 41.8 & \\
\hline High & 206 & 34.8 & 4626 & 35.2 & \\
\hline
\end{tabular}

$* * p<.01 ; * * * p<.001$ 


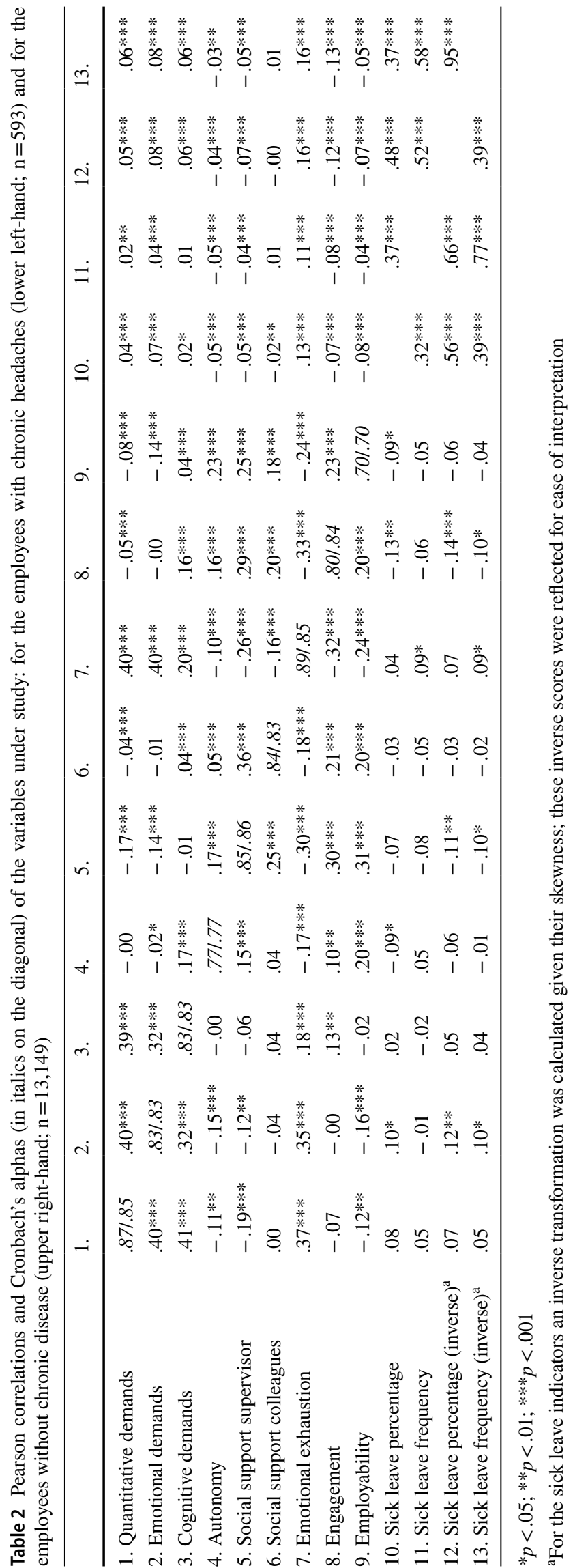

expectations: lower demands and higher resources were related to more favorable work ability indicators. An exception was the positive association $(r=.13, p<.01)$ between cognitive demands and work engagement.

The results of the multivariate analysis showed that controlling for gender, age, and educational level, psychosocial job characteristics explained a significant proportion of the variance in the work ability indicators in employees with chronic headaches, ranging from $+2 \%$ for sick leave to $+24 \%$ for emotional exhaustion (see Table 3 ). Regarding the demands, high quantitative demands and high emotional demands were predictive of emotional exhaustion, and the latter also for sick leave. Contrary to expectations, high cognitive demands were predictive of work engagement. The job resources were significant predictors for all outcomes under study: high autonomy and social support from supervisor and colleagues were associated with lower emotional exhaustion and higher employability. For work engagement, only the social support indicators were significantly related. Social support from supervisor proved to be related to a lower sick leave percentage and frequency.

Table 4 presents the results of the hierarchical regression analyses conducted to examine whether the associations between job characteristics and work ability indicators found for employees with chronic headaches differed from those in a sample without chronic disease. In only one instance a significant interaction between health status and job characteristics in the prediction of a work ability indicator was found (beta $=-.07, p<.001$ ): employees with chronic headaches showed a stronger negative association between social support from supervisor and emotional exhaustion. Simple slope analysis indicated that both for employees with chronic headaches and employees without chronic disease the association was significant (respectively beta $=-.38, p<.001$ and beta $=-.26, p<.001)$.

\section{Discussion}

In the current study, the relation between psychosocial job characteristics and indicators of work ability was examined in a sample of employees with chronic headaches. The hypotheses, based on the Job Demands-Resources model, were generally confirmed. High quantitative and emotional demands were associated with lower work ability, whereas high autonomy and high social support from colleagues and supervisor were overall associated with higher work ability. High cognitive demands, however, were related to high work engagement. This differential effect of job demands can be explained on the basis of current distinctions made in challenge versus hindrance demands [19], and challenge versus hindrance demands and threats [37]. All types of demands contribute to the 
Table 3 Work ability indicators regressed on job demands and job resources for employees with chronic headaches ( $\mathrm{n}=593$ ), controlling for age, gender, and educational level

\begin{tabular}{|c|c|c|c|c|c|}
\hline & $\begin{array}{l}\text { Emotional exhaustion } \\
\beta^{\mathrm{b}}\end{array}$ & $\begin{array}{l}\text { Work engagement } \\
\beta^{\mathrm{b}}\end{array}$ & $\begin{array}{l}\text { Employability } \\
\beta^{\mathrm{b}}\end{array}$ & $\begin{array}{l}\text { Sick leave percentage } \\
\beta^{\mathrm{b}}\end{array}$ & $\begin{array}{l}\text { Sick leave frequency } \\
\beta^{\mathrm{b}}\end{array}$ \\
\hline \multicolumn{6}{|l|}{ Block 1: control variables } \\
\hline Gender & $-.19 * * *$ & $.09 *$ & -.07 & $.12 * *$ & $.10^{*}$ \\
\hline Age $25-34$ years & -.05 & .09 & $-.19 * * *$ & .10 & .07 \\
\hline Age $35-44$ years & -.09 & $.12 *$ & $-.16^{* * *}$ & .05 & .04 \\
\hline Age $45-54$ years & -.04 & $.13^{* *}$ & $-.29 * * *$ & .01 & -.02 \\
\hline Age 55-65 years & -.04 & $.19 * * *$ & $-.26 * * *$ & .03 & .02 \\
\hline Educational level & $.09 *$ & $-.13 * * *$ & $.12 * *$ & .01 & .03 \\
\hline \multicolumn{6}{|c|}{ Block 2: job demands and resources } \\
\hline Quantitative demands & $.24 * * *$ & -.08 & -.06 & -.01 & -.02 \\
\hline Emotional demands & $.22 * * *$ & .02 & -.08 & $.10^{*}$ & .09 \\
\hline Cognitive demands & -.03 & $.19 * * *$ & .03 & .01 & .01 \\
\hline Autonomy & $-.11 * *$ & .07 & $.13 * * *$ & -.01 & .04 \\
\hline Support supervisor & $-.19 * * *$ & $.28 * * *$ & $.19 * * *$ & $-.10^{*}$ & $-.10^{*}$ \\
\hline Support colleagues & $-.10 * *$ & $.14 * * *$ & $.13 * * *$ & -.02 & -.01 \\
\hline Block 1 & $\Delta \mathrm{R}^{2}=.056^{* * *}$ & $\Delta \mathrm{R}^{2}=.020$ & $\Delta \mathrm{R}^{2}=.102 * * *$ & $\Delta \mathrm{R}^{2}=.025^{*}$ & $\Delta \mathrm{R}^{2}=.020$ \\
\hline Block 2 & $\Delta \mathrm{R}^{2}=.238 * * *$ & $\Delta \mathrm{R}^{2}=.158 * * *$ & $\Delta \mathrm{R}^{2}=.113^{* * *}$ & $\Delta \mathrm{R}^{2}=.023^{*}$ & $\Delta \mathrm{R}^{2}=.017$ \\
\hline \multirow[t]{2}{*}{ Full model } & $\mathrm{R}^{2}=.294 * * *$ & $\mathrm{R} 2=.178 * * *$ & $\mathrm{R}^{2}=.215^{* * *}$ & $\mathrm{R}^{2}=.048 * *$ & $\mathrm{R}^{2}=.037 *$ \\
\hline & $\mathrm{F}=20.13$ & $\mathrm{~F}=10.42$ & $\mathrm{~F}=13.22$ & $\mathrm{~F}=2.39$ & $\mathrm{~F}=1.82$ \\
\hline
\end{tabular}

$* p<.05 ; * * p<.01 ; * * * p<.001$

${ }^{a}$ For the sick leave indicators an inverse transformation was calculated given their skewness; these inverse scores were reflected for ease of interpretation

${ }^{b}$ Beta's in the final model are reported

energy depletion process; however challenge demands (e.g., cognitive demands, time pressure) can also have a positive effect on employees in terms of personal growth or development. Hindrance demands (e.g., role ambiguity, conflicts) are obstacles to personal growth and development and do not have positive effects, neither do threats. Threats are chances on personal harm or loss (e.g., emotional demands). Researchers might use the distinction to formulate more precise hypotheses in future research with the JD-R model. For employees with chronic headaches, social support from their supervisor proved to be a stronger predictor for emotional exhaustion than for employees without chronic disease. The importance of social support from colleagues and supervisors for employees with a chronic disease has been identified by various studies $[23,24,29]$. Finding this effect specifically for the supervisor might reflect that a trusting supportive supervisoremployee relationship enables an employee to adjust their work to their chronic illness, for instance in allowing flexibility, and enabling adaptations in for instance tasks and work schedule. Related to this, research has shown the relevance of disclosure: that employees inform and talk about their chronic disease and its consequences with colleagues and supervisor [38]. Disclosing can elicit support and lead to modifications regarding for instance tasks and work setting, which might help the chronically ill employee to manage their disease better $[39,40]$. A prerequisite for disclosure however would be a "psychologically safe" work environment, characterized by feelings of safety, interpersonal trust and mutual respect, hence providing an inclusive organizational climate for individuals with a chronic disease [41].

\section{Strengths and Limitations}

The current study was carried out on a large, representative sample of the Dutch working population, which contributes to the generalizability of the results. Furthermore, the use of valid measures for the key constructs can be considered a strength. However, some limitations need to be taken into account when interpreting the results. First, the study relies on self-report data, gathered cross-sectionally, which does not allow for causal interpretation of the findings. Furthermore, in the questionnaire limited information was gathered regarding the chronic condition. The sample examined in this study indicated that they had a chronic disease 'severe headaches/migraine', but no data 
Table 4 Work ability indicators regressed on health status (chronic headaches versus no chronic disease), job demands and resources, and the interaction between health status and job characteristics, controlling for age, gender, and educational level

\begin{tabular}{|c|c|c|c|c|c|}
\hline & $\begin{array}{l}\text { Emotional exhaustion } \\
\beta^{\text {a }}\end{array}$ & $\begin{array}{l}\text { Work engagement } \\
\beta^{\mathrm{a}}\end{array}$ & $\begin{array}{l}\text { Employability } \\
\beta^{\text {a }}\end{array}$ & $\begin{array}{l}\text { Sick leave percentage } \\
\beta^{\mathrm{c}}\end{array}$ & $\begin{array}{l}\text { Sick leave frequency } \\
\beta^{\mathrm{a}}\end{array}$ \\
\hline \multicolumn{6}{|l|}{ Block 1: control variables } \\
\hline Gender & $-.06 * * *$ & $.04 * * *$ & $-.07 * * *$ & $-.04 * * *$ & $-.03 * * *$ \\
\hline Age $25-34$ & .02 & $.06 * * *$ & $-.06^{* * *}$ & $-.06^{* * *}$ & $-.05 * * *$ \\
\hline Age $35-44$ & $-.02 *$ & $.11 * * *$ & $-.08 * * *$ & $-.03 *$ & -.00 \\
\hline Age $45-54$ & $-.03 * *$ & $.15^{* * *}$ & $-.16^{* * *}$ & .01 & $.04 * * *$ \\
\hline Age $55-65$ & $-.04 * * *$ & $.15 * * *$ & $-.21 * * *$ & .02 & $.05 * * *$ \\
\hline Educational level & .01 & $-.08 * * *$ & $.12 * * *$ & -.00 & $-.03 * * *$ \\
\hline \multicolumn{6}{|l|}{ Block 2: health status } \\
\hline $\begin{array}{l}\text { Chronic headaches versus no } \\
\text { chronic disease }\end{array}$ & $.06 * * *$ & $-.03 * * *$ & -.01 & $-.10 * * *$ & $-.11 * * *$ \\
\hline \multicolumn{6}{|c|}{ Block 3: job demands and resources } \\
\hline Quantitative demands & $.25 * * *$ & $-.06 * * *$ & $-.04 * * *$ & -.00 & -.00 \\
\hline Emotional demands & $.27 * * *$ & -.00 & $-.11 * * *$ & $-.05 * * *$ & $-.05 * * *$ \\
\hline Cognitive demands & $.03 * *$ & $.17 * * *$ & $.05 * * *$ & $-.04 * * *$ & $-.04 * * *$ \\
\hline Autonomy & $-.08 * * *$ & $.08 * * *$ & $.17 * * *$ & $.03 * * *$ & $.02 *$ \\
\hline Social support supervisor & $-.20 * * *$ & $.24 * * *$ & $.15 * * *$ & $.06 * * *$ & $.05 * * *$ \\
\hline Social support colleagues & $-.09 * * *$ & $.12 * * *$ & $.09 * * *$ & -.01 & -.02 \\
\hline \multicolumn{6}{|c|}{ Block 4: interaction health status $*$ job demands/resources ${ }^{\mathrm{b}}$} \\
\hline $\begin{array}{l}\text { Health status * social support } \\
\text { supervisor }\end{array}$ & $-.07 * * *$ & & & & \\
\hline Block 1 & $\Delta \mathrm{R}^{2}=.018^{* * *}$ & $\Delta \mathrm{R}^{2}=.021 * * *$ & $\Delta \mathrm{R}^{2}=.071^{* * *}$ & $\Delta \mathrm{R}^{2}=.009 * * *$ & $\Delta \mathrm{R}^{2}=.014 * * *$ \\
\hline Block 2 & $\Delta \mathrm{R}^{2}=.006^{* * *}$ & $\Delta \mathrm{R}^{2}=.001 * * *$ & $\Delta \mathrm{R}^{2}=.000$ & $\Delta \mathrm{R}^{2}=.010^{* * *}$ & $\Delta \mathrm{R}^{2}=.014 * * *$ \\
\hline Block 3 & $\Delta \mathrm{R}^{2}=.258 * * *$ & $\Delta \mathrm{R}^{2}=.135^{* * *}$ & $\Delta \mathrm{R}^{2}=.103^{* * *}$ & $\Delta \mathrm{R}^{2}=.011 * * *$ & $\Delta \mathrm{R}^{2}=.009 * * *$ \\
\hline Block 4 & $\Delta \mathrm{R}^{2}=.001 * * *$ & & & & \\
\hline \multirow[t]{2}{*}{ Full model } & $\mathrm{R}^{2}=.282 * * *$ & $\mathrm{R}^{2}=.157 * * *$ & $\mathrm{R}^{2}=.175^{* * *}$ & $\mathrm{R}^{2}=.030 * * *$ & $\mathrm{R}^{2}=.036 * * *$ \\
\hline & $\mathrm{F}=384.72$ & $\mathrm{~F}=195.33$ & $\mathrm{~F}=223.17$ & $\mathrm{~F}=32.21$ & $\mathrm{~F}=39.48$ \\
\hline
\end{tabular}

$* p<.05 ; * * p<.01 ; * * * p<.001$

${ }^{\text {a} B e t a ' s ~ i n ~ t h e ~ f i n a l ~ m o d e l ~ a r e ~ r e p o r t e d ~}$

${ }^{\mathrm{b}}$ Only significant interaction terms are included in the final model

${ }^{\mathrm{c}}$ For the sick leave indicators an inverse transformation was calculated given their skewness; these inverse scores were reflected for ease of interpretation

were available regarding potentially influential disease characteristics, such as the type of headache, the severity and frequency of headache episodes, and use of medication. In a similar vein, organizational characteristics (e.g., sector and type of organisation) and occupational characteristics (e.g., seniority and (non)managerial position) might influence the relationships found. In future research it would be valuable to overcome these limitations.

\section{Implications for Practice and Research}

When the current findings are confirmed longitudinally, the main implication for practice would be to reduce (excessive) quantitative and emotional demands, and enhance resources such as autonomy and worksite social support to establish/maintain good work ability in employees with this condition. A specific focus on establishing and maintaining good relationships between the employee and his/her supervisor is called for, as this proves to be an important resource for these employees. In terms of interventions, this would require a focus on both the individual employee, instigating empowerment and stimulating disclosure, and the supervisor/organization, to work together with the employee in establishing a work situation that enables the employee to function optimally given his/her chronic condition. Recent research has indicated that a training, focusing on empowerment of chronically ill employees was successful in enhancing self-efficacy and reducing fatigue, although it did not result in higher job retention [42]. Core components of the program were communication at the workplace, the exploration of 
work-related problems, and the development and implementations of solutions for these problems.

\section{Theoretical Implications}

From a theoretical perspective, the findings of this study are supportive for the notions of the Job DemandsResources model regarding the impact of psychosocial job characteristics in explaining health, motivation, and organizational outcomes [13, 22]. As such, this study confirms the validity of this model not only for the general working population, but also for a specific chronically ill sample. Furthermore, the differential effects of the various types of job demands found in this study underline the relevance of more recent distinctions between challenge, hindrance, and threat demands $[19,37]$.

\section{Future Research}

Given the high prevalence of chronic headache and the results of this study, a more detailed longitudinal research focusing on disease characteristics and psychosocial job conditions that contribute to work participation and functioning seems warranted. Relevant in this respect is the notion that job characteristics have also been found to play a role in the prevalence of headaches [43]. A longitudinal study with multiple measurements would provide the opportunity to further disentangle the association between job characteristics, headache severity and frequency, and work ability. Furthermore, to contribute to the development of work ability enhancing interventions it would be worthwhile to determine whether favorable changes in job characteristics (spontaneous and instigated) lead to improved work ability in employees with this condition.

\section{Conclusion}

Job demands and job resources are important for work ability in employees with chronic headaches. Furthermore, results suggest that these employees benefit more strongly from supervisor support than employees without chronic disease.

Funding TNO central government grant: grant for data-collection (Dutch government/Dutch Ministry of Economic Affairs); and The Joint Programme for Occupational Safety and Health in The Netherlands (JPOSH-nl) (Dutch Ministry of Social Affairs). The contribution of Roosmarijn M. C. Schelvis to the manuscript was partly funded by the Dutch Ministry of Social Affairs.

\section{Compliance with Ethical Standards}

Conflict of interest Margot P. van der Doef and Roosmarijn M. C. Schelvis declare that they have no conflict of interest.

Informed Consent An internal review board from the Netherlands Organisation for Applied Scientific Research TNO approved the NWCS. The study is in accordance with the Dutch Personal Data Protection Act and was carried out in collaboration with Statistics Netherlands. Participants received information about their privacy rights and the anonymity of their information. By participating in the study they consented to the use of their answers for research purposes.

Open Access This article is distributed under the terms of the Creative Commons Attribution 4.0 International License (http://creativeco mmons.org/licenses/by/4.0/), which permits unrestricted use, distribution, and reproduction in any medium, provided you give appropriate credit to the original author(s) and the source, provide a link to the Creative Commons license, and indicate if changes were made.

\section{References}

1. WHO. Factsheet headache disorders. Geneva: WHO; 2016.

2. Stovner LJ, Hagen K, Jensen R, Katsarava Z, Lipton RB, Scher AI, et al. The global burden of headache: a documentation of headache prevalence and disability worldwide. Cephalalgia. 2007;27(3):193-210.

3. Steiner TJ, Global Campaign C. Lifting the burden: the global campaign to reduce the burden of headache worldwide. J Neurol Sci. 2005;238:S92.

4. Hedenrud T, Love J, Staland-Nyman C, Hensing G. Frequent headache and work ability: a population-based study in Sweden. J Occup Environ Med. 2014;56(5):472-476.

5. Stewart WF, Ricci JA, Chee E, Morganstein D, Lipton R. Lost productive time and cost due to common pain conditions in the US workforce. J Am Med Assoc. 2003;290(18):2443-2454.

6. Stewart WF, Wood GC, Manack A, Varon SF, Buse DC, Lipton RB. Employment and work impact of chronic migraine and episodic migraine. J Occup Environ Med. 2010;52(1):8-14.

7. Burton WN, Landy SH, Downs KE, Runken MC. The impact of migraine and the effect of migraine treatment on workplace productivity in the United States and suggestions for future research. Mayo Clin Proc. 2009;84(5):436-445.

8. Steiner TJ, Birbeck GL, Jensen RH, Katsarava Z, Stovner LJ, Martelletti P. Headache disorders are third cause of disability worldwide. J Headache Pain. 2015;16:58.

9. Van der Doef M, Maes S. The job demand control (-support) model and physical health outcomes: a review of the strain and buffer hypothesis. Psychol Health. 1998;13(5):909-936.

10. Van der Doef M, Maes S. The job demand-control (-support) model and psychological well-being: a review of 20 years of empirical research. Work Stress. 1999;13(2):87-114.

11. Hausser JA, Mojzisch A, Niesel M, Schulz-Hardt S. Ten years on: a review of recent research on the job demand-control (-support) model and psychological well-being. Work Stress. 2010;24(1):1-35.

12. Bakker AB, Demerouti E, de Boer E, Schaufeli WB. Job demands and job resources as predictors of absence duration and frequency. J Vocat Behav. 2003;62(2):341-356.

13. Bakker AB, Demerouti E, Verbeke W. Using the job demandsresources model to predict burnout and performance. Hum Resour Manag. 2004;43(1):83-104. 
14. Karasek RA. Job demands, job decision latitude, and mental strain-implication for job redesign. Adm Sci Q. 1979;24(2):285-308.

15. Karasek RA, Theorell T. Healthy work: stress, productivity, and the reconstruction of working life. New York: Basic Books; 1990.

16. Bakker AB, Hakanen JJ, Demerouti E, Xanthopoulou D. Job resources boost work engagement, particularly when job demands are high. J Educ Psychol. 2007;99(2):274-284.

17. Van den Broeck A, Van Ruysseveldt J, Vanbelle E, De Witte H. The job demands-resources model: overview and suggestions for future research. In: Bakker AB, editors. Advances in positive organizational psychology. Bingley: Emerald Group Publishing Limited; 2013. pp. 83-105.

18. van Emmerik IJH, Schreurs B, de Cuyper N, Jawahar IM, Peeters MCW. The route to employability Examining resources and the mediating role of motivation. Career Dev Int. 2012;17(2-3):104-119.

19. Crawford ER, LePine JA, Rich BL. Linking job demands and resources to employee engagement and burnout: a theoretical extension and meta-analytic test. J Appl Psychol. 2010;95(5):834-848.

20. Seibt R, Spitzer S, Blank M, Scheuch K. Predictors of work ability in occupations with psychological stress. J Public Health. 2009;17(1):9-18.

21. Airila A, Hakanen JJ, Schaufeli WB, Luukkonen R, Punakallio A, Lusa S. Are job and personal resources associated with work ability 10 years later? The mediating role of work engagement. Work Stress. 2014;28(1):87-105.

22. Schaufeli WB, Bakker AB, Van Rhenen W. How changes in job demands and resources predict burnout, work engagement, and sickness absenteeism. J Organ Behav. 2009;30(7):893-917.

23. Donders N, Roskes K, van der Gulden JWJ. Fatigue, emotional exhaustion and perceived health complaints associated with workrelated characteristics in employees with and without chronic diseases. Int Arch Occup Environ Health. 2007;80(7):577-587.

24. Detaille SI, Haafkens JA, van Dijk FJH. What employees with rheumatoid arthritis, diabetes mellitus and hearing loss need to cope at work. Scand J Work Environ Health. 2003;29(2):134-142.

25. Schramm SH, Moebus S, Lehmann N, Galli U, Obermann $\mathrm{M}$, Bock E, et al. The association between stress and headache: a longitudinal population-based study. Cephalalgia. 2015;35(10):853-863.

26. Sauro KM, Becker WJ. The stress and migraine interaction. Headache. 2009;49(9):1378-1386.

27. Christensen JO, Knardahl S. Work and headache: a prospective study of psychological, social, and mechanical predictors of headache severity. Pain. 2012;153(10):2119-2132.

28. van den Berg TI, Robroek SJ, Plat JF, Koopmanschap MA, Burdorf A. The importance of job control for workers with decreased work ability to remain productive at work. Int Arch Occup Environ Health. 2011;84(6):705-712.
29. Varekamp I, van Dijk FJH. Workplace problems and solutions for employees with chronic diseases. Occup Med. 2010;60(4):287-293.

30. Van Zwieten MHJ, De Vroome EEM, Mol MEM, Mars GMJ, Koppes LLJ, Van den Bossche SNJ. The Netherlands Working Conditions Survey 2013: methodology and global results. Hoofddorp: TNO/CBS; 2014.

31. Karasek R, Brisson C, Kawakami N, Houtman I, Bongers P, Amick P. The Job Content Questionnaire (JCQ): an instrument for internationally comparative assessments of psychosocial job characteristics. J Occup Health Psychol. 1998;3(4):322-355.

32. Karasek RA. Job content questionnaire and user's guide. Lowell: University of Massachusetts, Lowell, Department of Work Environment; 1985.

33. Kristensen T, Borg V. Copenhagen Psychosocial Questionnaire (COPSOQ). Copenhagen: National Institute of Occupational Health; 2000.

34. Schaufeli WB, Van Dierendonck D. The Utrecht Burnout Scale (UBOS): test manual. Amsterdam: Harcourt; 2000.

35. Schaufeli WB, Bakker AB. Utrecht Work Engagement Scale (UWES). Preliminary manual. [Version 1.1, December 2004]. Utrecht: Utrecht University; 2004.

36. IBM Corp. IBM SPSS statistics for windows, version 24.0 ed. Armonk: IBM Corp; 2016.

37. Tuckey MR, Searle BJ, Boyd CM, Winefield AH, Winefield HR. Hindrances are not threats: advancing the multidimensionality of work stress. J Occup Health Psychol. 2015;20(2):131-147.

38. Munir F, Leka S, Griffiths A. Dealing with self-management of chronic illness at work: predictors for self-disclosure. Soc Sci Med. 2005;60(6):1397-1407.

39. Munir F, Randall R, Yarker J, Nielsen K. The influence of employer support on employee management of chronic health conditions at work. J Occup Rehabil. 2009;19(4):333-344.

40. Munir F, Yarker J, Haslam C, Long H, Leka S, Griffiths A, et al. Work factors related to psychological and health-related distress among employees with chronic illnesses. J Occup Rehabil. 2007;17(2):259-277.

41. Kirk-Brown A, Van Dijk P. An examination of the role of psychological safety in the relationship between job resources, affective commitment and turnover intentions of Australian employees with chronic illness. Int J Hum Resour Manag. 2016;27(14):1626-1641.

42. Varekamp I, Verbeek JH, de Boer A, van Dijk FJH. Effect of job maintenance training program for employees with chronic disease-a randomized controlled trial on self-efficacy, job satisfaction, and fatigue. Scand J Work Environ Health. 2011;37(4):288-297.

43. Santos IS, Griep RH, Alves MGM, Goulart AC, Lotufo PA, Barreto SM, et al. Job stress is associated with migraine in current workers: The Brazilian Longitudinal Study of Adult Health (ELSA-Brasil). Eur J Pain. 2014;18(9):1290-1297. 